\title{
Nanotrains and Self-Assembled Two-Dimensional Arrays Built from Carboranes Linked by Hydrogen Bonding of Dipyridones
}

\author{
Takashi Sasaki, Jason M. Guerrero, Ashley D. Leonard, and James M. Tour ( $\varangle)$ \\ Department of Chemistry, Department of Mechanical Engineering and Materials Science, Rice University, MS 222, 6100 Main St., \\ Houston, Texas 77005, USA \\ Received: 7 May 2008/ Revised: 18 September 2008/Accepted: 20 September 2008 \\ CTsinghua Press and Springer-Verlag 2008. This article is published with open access at Springerlink.com
}

\begin{abstract}
The strong hydrogen bonding ability of 2-pyridones were exploited to build nanotrains on surfaces. Carborane wheels on axles difunctionalized with 2-pyridone hydrogen bonding units were synthesized and displayed spontaneous formation of linear nanotrains by self-assembly on $\mathrm{SiO}_{2}$ or mica surfaces. Imaging using atomic force microscopy confirmed linear formations with lengths up to $5 \mu \mathrm{m}$ and heights within the range of the molecular height of the carborance-tipped axles.
\end{abstract}

\section{KEYWORDS}

Nanovehicles, nanotrains, 2-pyridone, hydrogen bonding, self-assembly

\section{Introduction}

Supramolecular engineering through noncovalent interactions is a promising tool for nanotechnological advances [1-3], such as potential applications in bioactive systems, sensors, field-effect transistors, thermoplastic elastomers, and optoelectronic devices [4-13]. With the use of interactions such as hydrogen bonding, $\pi-\pi$ stacking, van der Waals forces, hydrophobic/hydrophilic interactions, and Coulombic interactions, separately or in combinations, impressive structures including helices, cylindrical tubes, grids and cyclic assemblies [14-31] have been realized through specific molecular design. In particular, hydrogen bond interactions are attractive for obtaining well-defined supramolecular structures due to their spatial arrangement, selectivity and directionality [32].
Well-defined hydrogen-bonded structures have been realized through an understanding of biological systems [33]. Multiple binding sites seen in DNA nucleotide-like molecules offer increased binding strength and organization. However, simpler hydrogen bonding molecules should not be overlooked for generating self-assembled structures. Both 2-pyridone and its tautomer, hydroxypyridine, are well-documented for their ability to form hydrogen bonded dimeric structures in both solution and the solid phase [34, 35]. Although simple methods have been proposed to modify the bond strength of these dimers, such as cocrystallization between carboxylic acid units [36], there are few reports of imaging or the use of multiple 2-pyridone moieties to generate more complex assemblies [36-38].

There are two notable difficulties in imaging

Address correspondence to tour@rice.edu 
assembled structures of 2-pyridones. Firstly, imaging via scanning tunneling microscopy (STM), requires conductive substrates. The substrate-molecule interactions for 2-pyridones on metallic surfaces or metal atoms are stronger than the hydrogen bonds between 2-pyridone molecules [39-43], although there is one example of 2-pyridone species forming a dimeric 2-D adlayer imaged via STM on a modified, highly oriented pyrolytic graphite (HOPG) [38]. There are also atomically resolved STM images of other hydrogen bonding moieties that self-assemble into unique architectures but the substrate-molecule binding energies are usually lower [44, 45]. Despite the disadvantages of using STM as an imaging technique, its lateral resolution remains unparalleled. The second difficulty is that 2-pyridones form one molecule thin self-assembled structures that are difficult to image with good lateral resolution. To address these difficulties, in the present work, imaging using atomic force microscopy (AFM) allows for the use of a wide range of surfaces including non-conductive ones for imaging the self-assembly of 2-pyridones. The resolution in AFM imaging, however, depends upon both the in-plane $(X-Y)$ and $Z$-axis effects. The tip effect results in geometrical broadening (the approximate molecular width $+2 \times$ tip diameter) of the molecules [46]. Although there are reports suggesting the use of a single molecule as a tip [47], the sharpest tips currently available are at best $1 \mathrm{~nm}$ in radius [48, 49 ], thus resolution at the atomic or small molecule scale is extremely difficult. Other factors in AFM resolution are shot noise in the cantilever deflection photo detector and thermal vibration noise of the cantilever that occurs in the $Z$-axis. The combination of the noise effects contributes from $\sim 0.2$ to $0.7 \mathrm{~nm}$ in lost resolution depending on probe type, optical detection technique, and surface roughness [46], and thus resolving a monolayer of planar molecules is very difficult.
Our research in recent years has generated a class of surface-rolling molecules termed nanocars [5060]. Preferential rolling versus sliding motion was observed on surfaces with the incorporated wheels interacting strongly with the substrate. The wheels, fullerenes ( $1 \mathrm{~nm}$ in diameter) or $p$-carboranes $(0.8 \mathrm{~nm}$ in diameter) [61], that have been used can potentially serve as height-enhancing units for AFM imaging to enable imaging despite noise and tip effects. As an extension to the nanocar work, the synthesis of Monomer 1 containing 2-pyridones and a resulting self-assembled structure, a nanotrain, imaged by AFM is reported. For control purposes, Monomer 2 without the wheels was also synthesized.

\section{Results and discussion}

Compound 1 was synthesized using a known procedure [56], starting with the installation of the $p$-carborane wheels with the alkynyl bromide 3 , to give 4 (Scheme 1). This was followed by the deprotection of the triisopropylsilylacetylene (TIPSacetylene) groups to give 5. Finally, Pd-catalyzed coupling of the 2-pyridone moieties gave nanotrain Monomer 1 (Fig. 1). Similarly, the dialkynyl benzene precursor 6 [62] was coupled via a simple Sonogashira protocol to obtain control Monomer 2 (Scheme 2). In some cases, the NMR analyses do not give first order spectra. We assume that there is

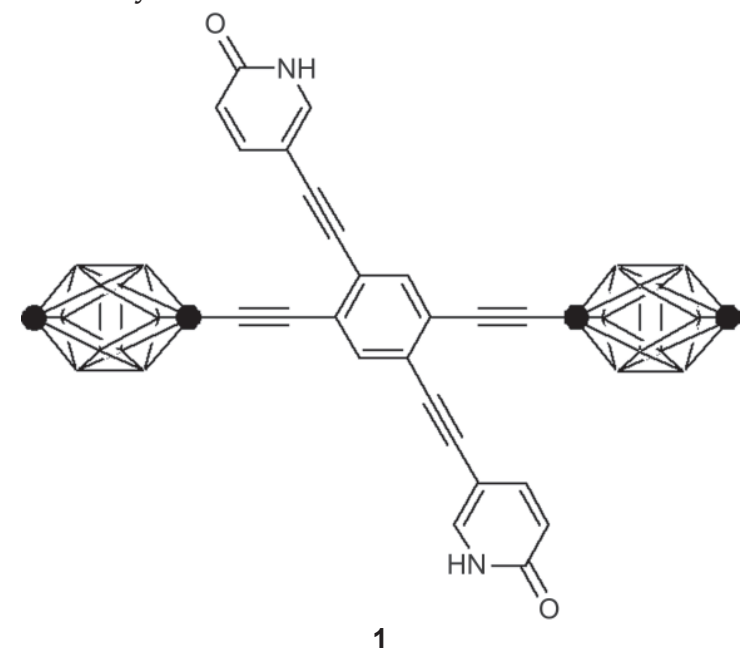

(a)

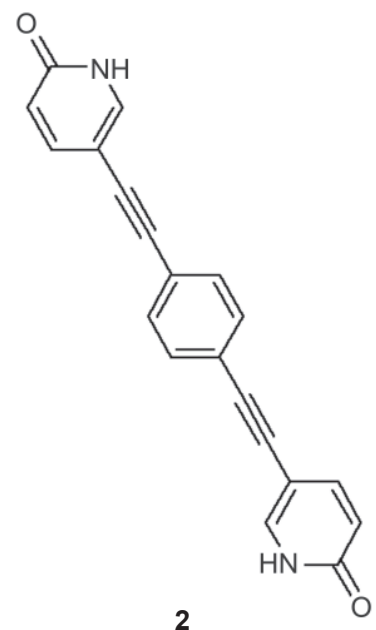

(b)
Figure 1 Target monomer molecules for hydrogen bonded self-assembled structures. Monomer 1 contains $p$-carborane moieties to produce heightened images for AFM analysis. Monomer $\mathbf{2}$ serves as a control. The carborane has a $\mathrm{B}-\mathrm{H}$ at each vertex except the darkened positions that have $\mathrm{C}-\mathrm{H}$ para and $\mathrm{C}$ ipso to the alkyne 


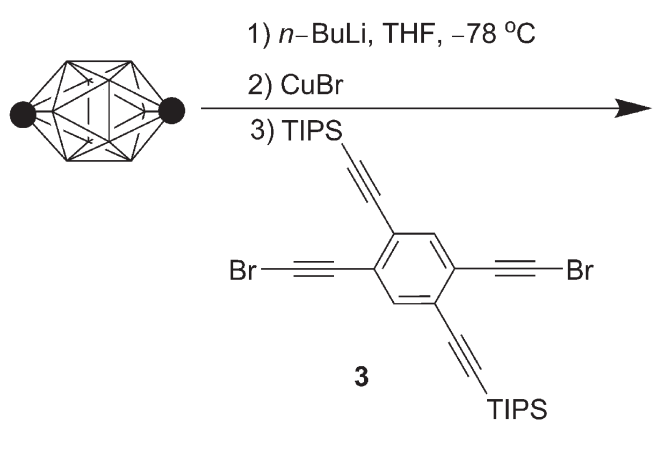

$71 \%$
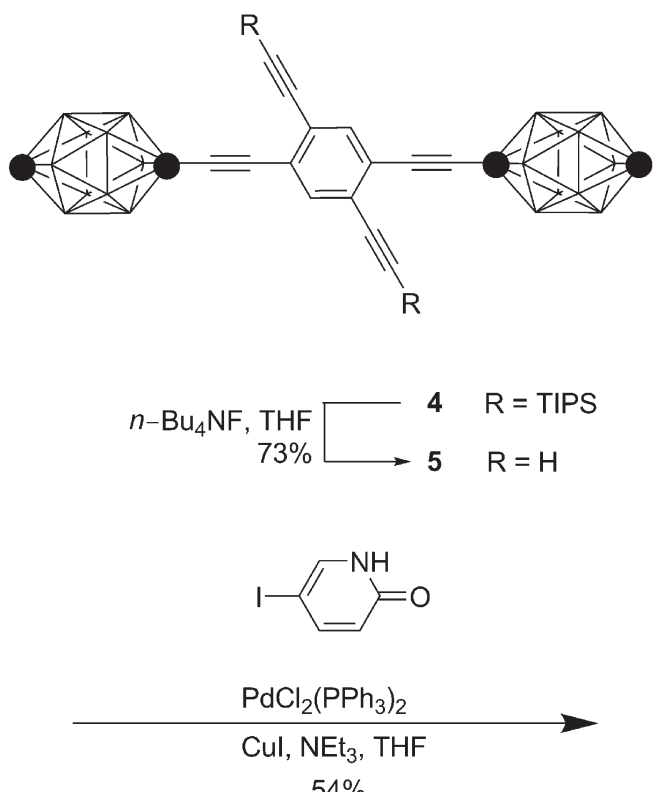

$54 \%$

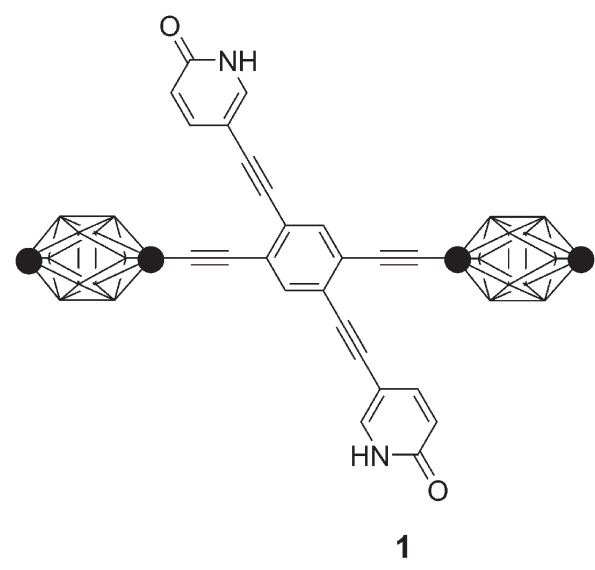

Scheme 1 Synthesis of Compound 1 some degree of hydrogen bonding and / or tautomerization detected in the NMR analyses, and that causes peak broadening as well as the presence/absence of peaks.

To study the self-assembling nature of these 2-pyridone derivatives, a $10 \mu \mathrm{mol} / \mathrm{L}$ solution of the monomer in tetrahydrofuran (THF) was drop-cast onto a $\mathrm{SiO}_{2}$ or a freshly cleaved mica surface, vacuum dried (in the case of the samples on $\mathrm{SiO}_{2}$; vacuum drying the mica samples did not produce good results), and observed by AFM ${ }^{1}$. Conventional tapping-mode etched silicon probes (TESP) with tip sizes of approximately $25 \mathrm{~nm}$ in diameter were used in ambient atmosphere. For superior lateral resolution, high resolution (MikroMasch HI-RES) tips of diameter 1 $\mathrm{nm}$ were also used under similar conditions. Without the height-enhancing carborane structures, Monomer $\mathbf{2}$ showed no recognizable self-assembled structures anywhere on the $\mathrm{SiO}_{2}$ surface (Fig. 2(a)) whereas Monomer 1 self-assembled into linear structures (Figs. 2(b)-(d)) with lengths as long as $\sim 5 \mu \mathrm{m}$. Heights were in the range of $0.7-1.6 \mathrm{~nm}$, within the range of the molecular height of carboranes or carboranes with axles [61]. Although imaging of the nanotrain using MikroMasch HI-RES tips on mica surfaces indeed provided sharper images than their conventional counterparts, (Fig. S-1 in the Electronic Supplementary Material (ESM)), the data from Figs. 2 and S-1 are in agreement that intra- or interchain interactions arising from folding, or multiple chains bound side-to-side, are quite possible due to the widths of the observed formations. Unfortunately, in an effort to obtain images of single nanotrains, AFM using the HI-RES tip of samples deposited from toluene or toluene/ THF on mica did not produce usable images ${ }^{2}$.

There are three possible combinations of hydrogen bonding patterns through rotation about the alkyne bond linking the 2-pyridone to the rigid core (Fig. 3). In Fig. 3(a), with an assembly of the monomer in the cis conformation only, where both of the 2-pyridones are facing the same side, a linear chain is produced. In Fig. 3(b), a linear chain is again produced with all the monomers in the trans conformation and the pyridones facing the opposite directions. In Fig. 3(c), the combination of both the cis and the trans confirmations of 1 linking randomly can result

\footnotetext{
${ }^{1}$ Images taken by the AFM were processed using Nanoscope 5.30r1. Nanotrain formation was unaffected when switching the substrate from $\mathrm{SiO}_{2}$ to mica.

${ }^{2}$ In an attempt to avoid possible $\pi$-stacking interactions, drop-casting was also attempted using benzene and toluene as solvent but no trains were observed, presumably due to the low solubility of the molecules.
} 


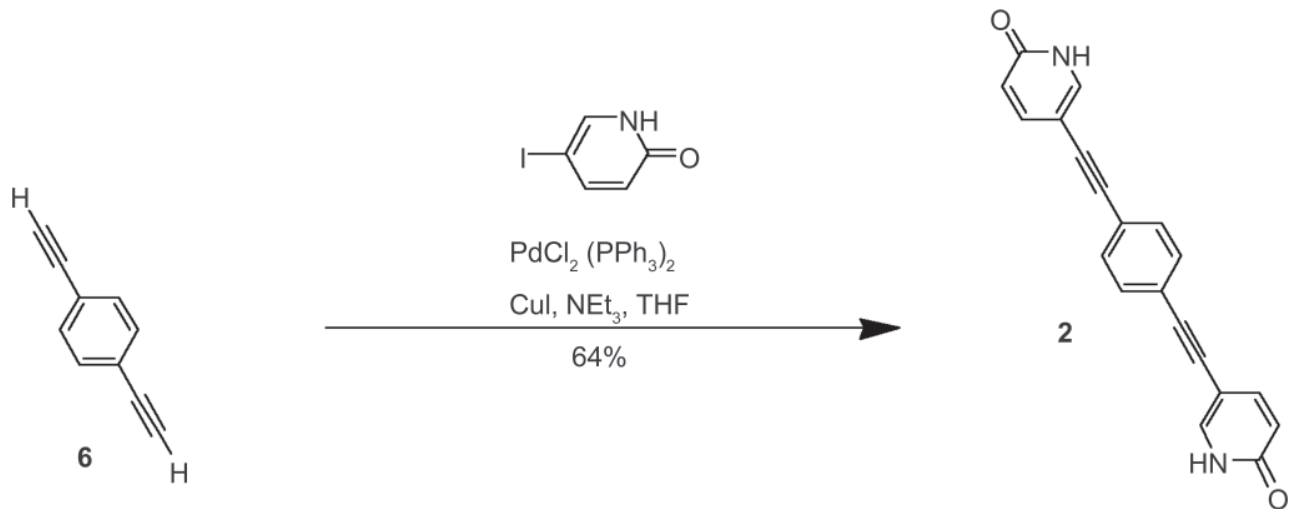

Scheme 2 Synthesis of Compound $\mathbf{2}$

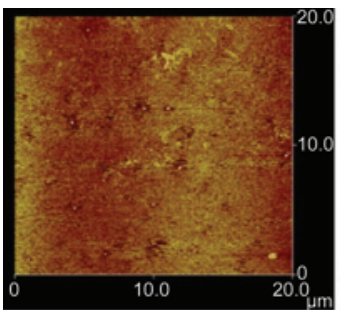

(a)

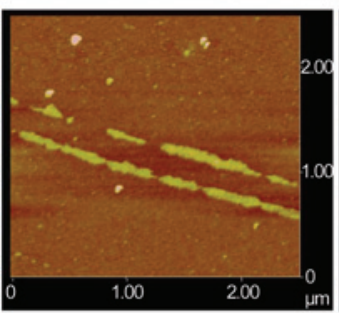

(c)

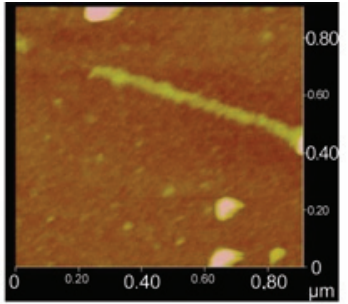

(b)

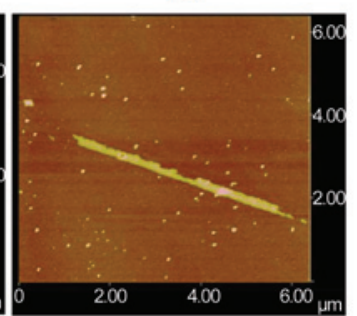

(d)

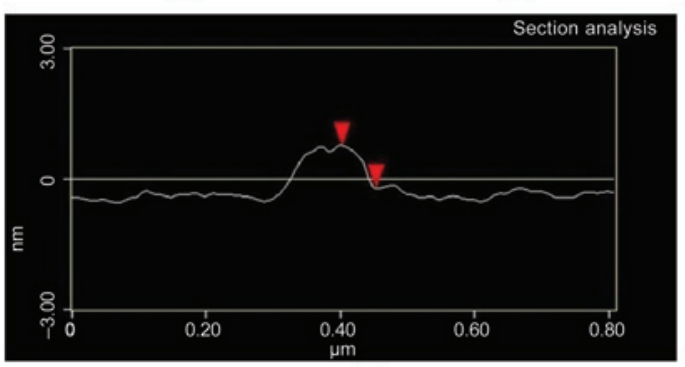

(e)

Figure 2 (a)-(d) Four AFM images of drop-cast nanotrain 1 and control 2 in THF $\left(1 \times 10^{-5} \mathrm{~mol} / \mathrm{L}\right)$ on $\mathrm{SiO}_{2}$, scan rate $1.30 \mathrm{~Hz}$, sample resolution 512. (a) 2, $20.0 \mu \mathrm{m} \times 20.0 \mu \mathrm{m}$; (b) 1, $0.90 \mu \mathrm{m} \times 0.90 \mu \mathrm{m}$; (c) 1, $2.5 \mu \mathrm{m} \times 2.5 \mu \mathrm{m}$; (d) 1, $6.5 \mu \mathrm{m} \times 6.5 \mu \mathrm{m}$; (e) typical height profile of the self-assembled nanotrain

in a curved structure. We are not able to resolve the individual moieties responsible for hydrogen bonding, and all three structures could co-exist. In a report of similar hydrogen bonding via bispyridone structures linked by alkynes to a rigid core, X-ray crystallography showed a preferential planar polymeric motif based on the trans pattern [36].

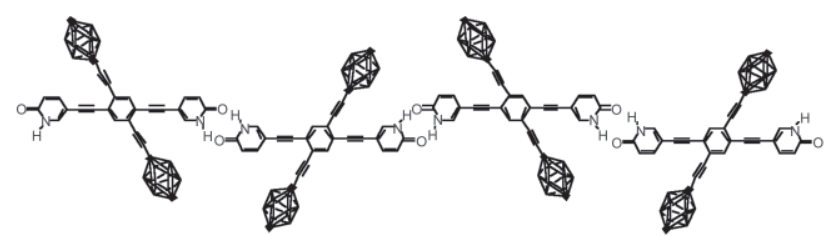

(a)

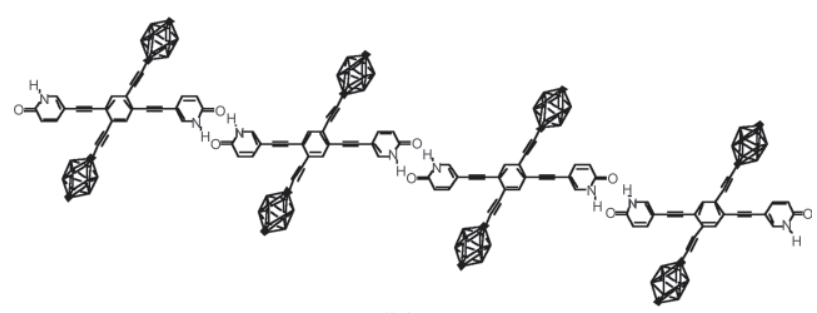

(b)

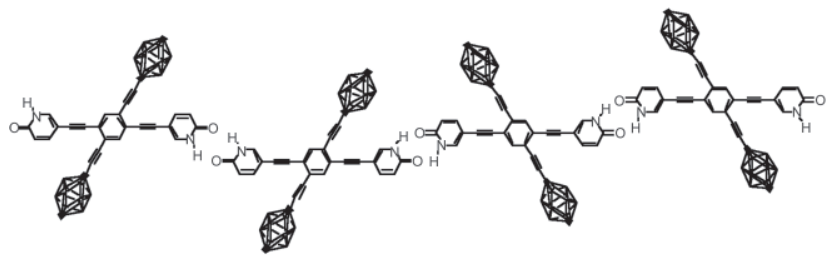

(c)

Figure 3 Nanotrain configurations from Monomer 1. Three possible patterns of 2-pyridone self-assembly: (a) cis only, linear assembly; (b) trans only, linear diagonal assembly; (c) combination of cis and trans in random fashion, which can result in curvature

This result is based on a closely packed crystalline structure, whereas the diluted condition on the surface presents a different environment, and thus the exact hydrogen bonding scheme is unknown.

\section{Experimental}

General methods. All reactions were performed under an atmosphere of nitrogen unless otherwise stated. Reagent grade THF was distilled from sodium 
benzophenone ketyl. Triethylamine (TEA) was distilled over $\mathrm{CaH}_{2}$. Flash column chromatography was performed using 230-400 mesh silica gel from EM Science. TLC was performed using glass plates precoated with silica gel $40 \mathrm{~F}_{254}$ purchased from EM Science. NMR analysis was done at $500 \mathrm{MHz}$ with shifts reported relative to tetramethylsilane (TMS); $\mathrm{s}=$ singlet, $\mathrm{d}=$ doublet, $\mathrm{m}=$ multiplet, $\mathrm{dd}=$ doublet of doublets.

Compound 1 (Fig. 1(a)). To an oven-dried roundbottom flask equipped with a magnetic stirrer bar was added Compound 5 [56] (0.054 g, $0.118 \mathrm{mmol})$, 2-hydroxy-5-iodopyridine $(0.057 \mathrm{~g}, 0.259 \mathrm{mmol})$, $\mathrm{PdCl}_{2}\left(\mathrm{PPh}_{3}\right)_{2}(0.003 \mathrm{~g}, 0.004 \mathrm{mmol})$, and $\mathrm{CuI}(0.002$ g, $0.011 \mathrm{mmol})$. THF $(30 \mathrm{~mL})$ and TEA $(2 \mathrm{~mL})$ were added and the mixture was stirred at rt overnight. Upon completion, the reaction was quenched with a saturated solution of $\mathrm{NH}_{4} \mathrm{Cl}$. The organic layer was diluted with ethyl acetate and was washed with water. The aqueous layers were extracted with ethyl acetate and $\mathrm{CH}_{2} \mathrm{Cl}_{2}(2 \times)$. The combined organic layers were dried over $\mathrm{MgSO}_{4}$, filtered, and the solvent was removed from the filtrate in vacuo to afford the crude product, which was purified by $\mathrm{SiO}_{2}$ column chromatography using $10 \% \mathrm{MeOH}$ in ethyl acetate. Removing the solvent in vacuo afforded a yellow-orange solid 1 (Fig. 1(a))(0.037 g, 54\%). FTIR 3050, 2947, 2860, 2621, 1725, 1654, 1595, 1529, 1437, 1176, 1122, $829 \mathrm{~cm}^{-1}$; ${ }^{1} \mathrm{H}$ NMR $(500 \mathrm{MHz}$, $\left.\mathrm{CDCl}_{3}, \mathrm{ppm}\right) \delta 7.61-7.68(\mathrm{~m}, 2 \mathrm{H}), 7.60-7.51(\mathrm{~m}, 1 \mathrm{H})$, $7.57(\mathrm{~s}, 2 \mathrm{H}), 7.49-7.42(\mathrm{~m}, 2 \mathrm{H}), 6.42(\mathrm{~d}, 1 \mathrm{H}, J=10.23$ $\mathrm{Hz}), 4.50-1.00$ (m, 22H); ${ }^{1} \mathrm{H}$ NMR (500 MHz, MeOD ppm) $\delta 7.67(\mathrm{dd}, 1 \mathrm{H}, J=2.55 \mathrm{~Hz}, J=9.53 \mathrm{~Hz}), 7.63-$ $7.56(\mathrm{~m}, 4 \mathrm{H}), 7.54-7.48(\mathrm{~m}, 2 \mathrm{H}), 6.33(\mathrm{dd}, 1 \mathrm{H}, J=0.66$ $\mathrm{Hz}, J=9.53 \mathrm{~Hz}), 4.50-1.00(\mathrm{~m}, 22 \mathrm{H}) ;{ }^{13} \mathrm{C}$ NMR $(125$ $\left.\mathrm{MHz} \mathrm{CDCl}_{3}\right) \delta 149.2,140.1,132.5,132.1,132.0,132.0$, 131.7, 128.6, 128.5, 122.1, 122.1, 103.7, 66.9, 66.1; EIHRMS $m / z$ calcd for $\mathrm{C}_{28} \mathrm{H}_{32} \mathrm{~N}_{2} \mathrm{O}_{2} 644.79$, found 644.78 .

Compound 2 (Fig. 1(b)). To an oven-dried roundbottom flask equipped with a magnetic stirrer bar was added Compound 6 [62] (0.080 g, $0.634 \mathrm{mmol})$, 2-hydroxy-5-iodopyridine $(0.308 \mathrm{~g}, 1.39 \mathrm{mmol})$, $\mathrm{PdCl}_{2}\left(\mathrm{PPh}_{3}\right)_{2}(0.008 \mathrm{~g}, 0.011 \mathrm{mmol})$, and $\mathrm{CuI}(0.005$ $\mathrm{g}, 0.026 \mathrm{mmol})$. THF $(30 \mathrm{~mL})$ and TEA $(5 \mathrm{~mL})$ were added and the mixture was stirred at rt overnight. Upon completion, the reaction was quenched with a saturated solution of $\mathrm{NH}_{4} \mathrm{Cl}$. The organic layer was then diluted with ethyl acetate and was washed with water. The aqueous layers were extracted with ethyl acetate and $\mathrm{CH}_{2} \mathrm{Cl}_{2}(2 \times)$. The combined organic layers were dried over $\mathrm{MgSO}_{4}$, filtered, and the solvent was removed from the filtrate in vacuo to afford the crude product, which was purified by $\mathrm{SiO}_{2}$ column chromatography using $10 \% \mathrm{MeOH}$ in ethyl acetate. Removing the solvent in vacuo afforded a yellow orange solid 2 (Fig. 1(b)) (0.127 g, 64\%). FTIR 2930, 2849, 1643, 1600, 1567, 1513, 1410, 1247, 992, $661 \mathrm{~cm}^{-1}$; ${ }^{1} \mathrm{H}$ NMR (500 MHz, MeOD, ppm) $\delta 7.65(\mathrm{~m}, 4 \mathrm{H}), 7.46$ $(\mathrm{d}, 2 \mathrm{H}, J=8.73 \mathrm{~Hz}), 7.42(\mathrm{~s}, 2 \mathrm{H}), 6.49(\mathrm{~d}, 2 \mathrm{H}, J=9.72$ $\mathrm{Hz}$ ); the solubility was too low for ${ }^{13} \mathrm{C}$ NMR analysis; EI-HRMS $m / z$ calcd for $\mathrm{C}_{20} \mathrm{H}_{12} \mathrm{~N}_{2} \mathrm{O}_{2} 312.09$, found 312.09 .

\section{Conclusions}

In summary, self-assembled structures using simple but strong hydrogen bonding of 2-pyridone moieties have been designed, synthesized and imaged by AFM. A linear nanotrain was synthesized with two hydrogen bonding sites at opposite positions. Imaging of the nanotrain at the atomic level on modified substrates is underway with the eventual goal of imaging concerted rolling motion.

\section{Acknowledgements}

We thank the Welch Foundation, Zyvex Corporation, American Honda Motor Co., the NSF NIRT 07111302, and the NSF Penn State MRSEC for financial support. The NSF, CHEM 0075728, provided partial funding for the $400 \mathrm{MHz}$ NMR spectrometer. We thank Drs. I. Chester of FAR Research, Inc. and R. Awartari of Petra Research, Inc. for providing trimethylsily lacetylene (TMSA).

Electronic Supplementary Material: Supplementary material including spectroscopic data (FTIR, ${ }^{1} \mathrm{H}$ NMR, ${ }^{13} \mathrm{C}$ NMR) for Compounds $\mathbf{1}$ and 2 and the AFM images of 1 on mica is available in the online version of this article at http://dx.doi.org/10.1007/ s12274-008-8041-4 and is accessible free of charge. 


\section{References}

[1] Whitesides, G. M.; Mathias, J. P.; Seto, C. T. Molecular self-assembly and nanochemistry: A chemical strategy for the synthesis of nanostructures. Science 1991, 254, 1312-1319.

[2] Lindsey, J. S. Self-assembly in synthetic routes to molecular devices. Biological principles and chemical perspectives: A review. New J. Chem. 1991, 15, 153180.

[3] Philp, D.; Stoddart, J. F. Self-assembly in natural and unnatural systems. Angew. Chem. Int. Ed. Engl. 1996, 35, 1154-1196.

[4] Bong, D. T.; Clark, T. D.; Granja, J. R.; Ghadiri, M. R. Selfassembling organic nanotubes. Angew. Chem., Int. Ed. 2001, 40, 988-1011.

[5] Miao, Q.; Lefenfeld, M.; Nguyen, T. -Q.; Siegrist, T.; Kloc, C.; Nuckolls, C. Self-assembly and electronics of dipolar linear acenes. Adv. Mater. 2005, 17, 407-412.

[6] Yip, H, -L.; Ma, H.; Jen, A. K. -Y.; Dong, J.; Parviz, B. A. Two-dimensional self-assembly of 1-pyrylphosphonic acid: Transfer of stacks on structured surface. J. Am. Chem. Soc. 2006, 128, 5672-5679.

[7] Sirringhaus, H.; Brown, P. J.; Friend, R. H.; Nielsen, M. M.; Bechgaard, K.; Langeveld-Voss, B. M. W.; Spiering, A. J. H.; Jamssen, R. A. J.; Meijer, E. W.; Herwig, P., et. al. Two-dimensional charge transport in self-organized, high-mobility conjugated polymers. Nature 1999, 401, 685-688.

[8] van de Craats, A. M.; Stutzmann, N.; Bunk, O.; Nielsen, M. M.; Watson, M.; Müllen, K.; Chanzy, H. D.; Sirringhaus, H.; Friend, R. H. Meso-epitaxial solutiongrowth of self-organizing discotic liquid-crystalline semiconductors. Adv. Mater. 2003, 15, 495-499.

[9] Faccheti, A.; Mushrush, M.; Yoon, M. H.; Hutchison, G. R.; Ratner, M. A.; Marks, T. J. Building blocks for n-type molecular and polymeric electronics. Perfluoroalkylversus alkyl-functionalized oligothiophenes $(n T ; n=2-$ 6) Systematics of thin film microstructure, semiconductor performance, and modeling of majority charge injection in field-effect transistors. J. Am. Chem. Soc. 2004, 126, 13859-13874.

[10] Wu, Y.; Li, Y.; Gardner, S.; Ong, B. S. Indolo[3,2b]carbazole-based thin-film transistors with high mobility and stability. J. Am. Chem. Soc. 2005, 127, 614-618.

[11] Kautz, H.; van Beek, D. J. M.; Sijbesma, R. P.; Meijer, E. W.
Cooperative end-to-end and lateral hydrogen-bonding motifs in supramolecular thermoplastic elastomers. Macromolecules 2006, 39, 4265-4267.

[12] Schmidt-Mende, L.; Fehtenkotter A.; Müllen, K.; Moons, E.; Friend, R. H.; Mackenzie, J. D. Self-organized discotic liquid crystals for high-efficiency organic photovoltaics. Science 2001, 293, 1119-1122.

[13] Yang, X. N.; van Duren, J. K. J.; Rispens, M. T.; Hummelen, J. C.; Janssen, R. A. J.; Michels, M. A. J.; Loos, J. Crystalline organization of a methanofullerene as used for plastic solar-cell applications. Adv. Mater. 2004, 16, 802-806.

[14] Koert, U.; Harding, M. M.; Lehn, J. M. DNH deoxyribonucleohelicates: Self assembly of oligonucleosidic doublehelical metal complexes. Nature 1990, 346, 339-342.

[15] Engelkamp, H.; Middelbeek, S.; Nolte, R. J. M. Selfassembly of disk-shaped molecules to coiled-coil aggregates with tunable helicity. Science 1999, 284, 785-788

[16] Hirschberg, J. H. K. K.; Brunsverld, L.; Ramzi, A.; Vekemans, J. A. J. M.; Sijbesma, R. P.; Meijer, E. W. Helical self-assembled polymers from cooperative stacking of hydrogen-bonded pairs. Nature 2000, 407, 167-170.

[17] Percec, V.; Glodde, M.; Bera, T. K.; Miura, Y.; Shiyanovskaya, I.; Singer, K. D.; Balagurusamy, V. S. L.; Heiney, P. A.; Schnell, I.; Rapp, A., et al. Self-organization of supramolecular helical dendrimers into complex electronic materials. Nature 2002, 419, 384-387.

[18] Yamamoto, T.; Fukushima, T.; Yamamoto, Y.; Kosaka, A.; Jin, W.; Ishii, N.; Aida, T. Stabilization of a kinetically favored nanostructure: Surface ROMP of self-assembled conductive nanocoils from a norbornene-appended hexa-peri-hexabenzocoronene. J. Am. Chem. Soc. 2006, 128, 14337-14340.

[19] Jonkheijm, P.; Miura, A.; Zdanowska, M.; Hoeben, F. J. M.; Feyter, S. D.; Schenning, A. P. H. J.; de Schryver, F. C.; Meijer, E. W. $\pi$-Conjugated oligo-(p-phenylenevinylene) rosettes and their tubular self-assembly. Angew. Chem. Int. Ed. 2004, 43, 74-78.

[20] Ghadiri, M. R.; Granja, J. R.; Milligan, R. A.; McRee, D. E.; Khazanovich, N. Self-assembling organic nanotubes based on a cyclic peptide architecture. Nature, 1993, 366, 324-327.

[21] Yan, D. Y.; Zhou, Y. F.; Hou, J. Supramolecular selfassembly of macroscopic tubes. Science 2004, 303, 65- 
67.

[22] Baxter, P. N. W.; Lehn, J. M.; Fischer, J.; Youinou, M. Selfassembly and structure of a $3 \times 3$ inorganic grid from nine silver ions and six ligand components. Angew. Chem. Int. Ed. Engl. 1994, 33, 2284-2287.

[23] Weissbuch, I.; Baxter, P. N. W.; Cohen, S.; Cohen, H.; Kjaer, K.; Howes, P. B.; Als-Nielsen J.; Hanan, G. S.; Schubert, U. S.; Lehn, J, M., et al. Self-assembly at the air-water interface: In-situ preparation of thin films of metal ion grid architectures. J. Am. Chem. Soc. 1998, 120, 4850-4860.

[24] Ruben, M.; Rojo, J.; Romero-Saluguero, F. J.; Uppadine, L. H.; Lehn, J. M. Grid-type metal ion architectures: Functional metallosupramolecular arrays. Angew. Chem., Int. Ed. 2004, 43, 3644-3662.

[25] Zerowski, J. A.; Whitesides, G. M. Steric control of secondary, solid-state architecture in 1:1 complexes of melamines and barbiturates that crystallize as crinkled tapes. J. Am. Chem. Soc. 1994, 116, 4298-4304.

[26] Ranganathan, A.; Pedireddi, V. R.; Rao, C. N. R. Hydrothermal synthesis of organic channel structures: 1:1 hydrogen-bonded adducts of melamine with cyanuric and trithiocyanuric acids. J. Am. Chem. Soc. 1999, 121, 1752-1753.

[27] Prins, L. J.; de Jong, F.; Timmerman, P.; Reinhoudt, D. N. An enantiomerically pure hydrogen-bonded assembly. Nature 2000, 408, 181-184.

[28] Whitesides, G. M.; Simanek, E. E.; Mathias, J. P.; Seto, C. T.; Chin, D. N.; Mammen, M.; Gordon, D. M. Noncovalent synthesis: Using physical-organic chemistry to make aggregates. Acc. Chem. Res. 1995, 28, 37-44.

[29] Highfill, M. L.; Chandrasekaran, A.; Lynch, D. E.; Hamilton, D. A. Superstructural variety from an alkylated triazine: Formation of one-dimensional hydrogen-bonded arrays or cyclic rosettes. Cryst. Growth Des. 2002, 2, 1520.

[30] Kolotuchin, S. V.; Zimmerman, S. C. Self-assembly mediated by the donor-donor-acceptor-acceptoracceptor-donor (DDA.AAD) hydrogen-bonding motif: Formation of a robust hexameric aggregate. J. Am. Chem. Soc. 1998, 120, 9092-9093.

[31] Marsh, A.; Silvestri, M.; Lehn, J. M. Self-complementary hydrogen bonding heterocycles designed for the enforced self-assembly into supramolecular macrocycles. Chem. Commun. 1996, 1527-1528.

[32] Jeffrey, G. A. An Introduction to Hydrogen Bonding;
Oxford University Press: Oxford, 1997.

[33] Atwood, J. L.; Davies, J. E. D.; MacNicol, D. D.; Vögtle, F.; Lehn, J. -M. Comprehensive Supramolecular Chemistry; Pergamon: New York, 1996.

[34] Simard, M.; Su, D.; Wuest, J. D. Use of hydrogen bonds to control molecular aggregation. Self-assembly of threedimensional networks with large chambers. J. Am. Chem. Soc. 1991, 113, 4696-4698.

[35] Edwards, M. R.; Jones, W.; Motherwell, W. D. S. Influence of dicarboxylic acid structure on tape networks in cocrystals of 2-pyridone. Cryst. Eng. 2002, 5, 25-36.

[36] Ducharme, Y.; Wuest, J. D. Use of hydrogen bonds to control molecular aggregation: Extensive, selfcomplementary arrays of donors and acceptors. J. Org. Chem. 1988, 53, 5787-5789.

[37] Gallant, M.; Viet, M. T. P.; Wuest, J. D. Use of hydrogen bonds to control molecular aggregation: Association of dipyridones joined by flexible spacers. J. Org. Chem. 1991, 56, 2284-2286.

[38] Heinz, R.; Rabe, J. P.; Meister, W. -V.; Hoffmann, S. Structure and dynamics of two-dimensional adlayers of a 2-pyridone smectogen studied by STM. Thin Solid Films 1995, 264, 246-249.

[39] Thwaite, S.; Schier, A.; Schmidbaur, H. The auration of 2-hydroxy-pyridine (2-pyridone): Preparative and structural studies and a comparison with reactions of related aliphatic O,N-donors. Inorg. Chim. Acta. 2004, 357, 1549-1557.

[40] Miyabayashi, T.; Hara, T.; Yamagata, T.; Mashima, K. Chlorido(6-diphenylphosphino-2-pyridonato- $\kappa 2 \mathrm{P}, \mathrm{N})(6$ diphenylphosphino-2-hydroxypyridine- $\kappa 2 \mathrm{P}, \mathrm{N}$ )hydrido iridium(III) chloroform 1.896-solvate. Acta Crystallogr. E 2007, 63, m576-m578.

[41] Nichol, G. S.; Clegg, W. Complexes of 6-methyl-2pyridone with the alkaline earth metals magnesium, strontium and barium: Synthesis and structural characterisation. Inorg. Chim. Acta 2006, 359, 34743480.

[42] Murugavel, R.; Kuppuswamy, S.; Boomishankar, R.; Steiner, A. Hierarchical structures built from a molecular zinc phosphate core. Angew. Chem. Int. Ed. 2006, 45, 5536-5540.

[43] Chuchuryukin, A. V.; Chase, P. A.; Mills, A. M.; Lutz, M.; Spek, A. L.; van Klink, G. P. M.; van Koten, G. Hydroxyand mercaptopyridine pincer platinum and palladium complexes generated by silver-free halide abstraction. 
Inorg. Chem. 2006, 5, 2045-2054.

[44] Barth, J. V.; Constantini, G.; Kern, K. Engineering atomic and molecular nanostructures at surfaces. Nature 2005, 437, 671-679.

[45] Barth, J. V.; Weckesser, J.; Cai, C.; Günter, P.; Bürgi, L.; Jeandupeux O.; Kern, K. Building supramolecular nanostructures at surfaces by hydrogen bonding. Angew. Chem. Int. Ed. 2000, 39, 1230-1234.

[46] West, P.; Ross. A. An Introduction to Atomic Force Microscopy Modes. Pacific Nanotoechnology, Inc. http://www.pacificnanotech.com/afm-modes_materialproperty-modes.html (accessed 2006)

[47] Takamatsu, D.; Yamakoshi, Y.; Fukui, K. Control of probe function in noncontact atomic force microscopy using photo-responsive molecular tip. Surf. Sci. Nanotech. 2006, 4, 249-253.

[48] Marcus, R. B.; Ravi, T. S.; Gmitter, T.; Chin, K.; Orvis, W. J.; Ciarlo, D. R.; Hunt, C. E.; Trujillo, J. Formation of silicon tips with $<1 \mathrm{~nm}$ radius. Appl. Phys. Lett. 1990, 56, 236238.

[49] HI-RES tips with tip radius of $\sim 1 \mathrm{~nm}$ are commercially available from MikroMasch, Inc., http://www.spmtips. com (accessed 21 October, 2008)

[50] Shirai, Y.; Osgood, A. J.; Zhao, Y.; Kelly, K. F.; Tour, J. M. Directional control in thermally driven single-molecule nanocars. Nano Lett. 2005, 5, 2330-2334.

[51] Shirai, Y.; Osgood, A. J.; Zhao, Y.; Yao, Y.; Saudan, L.; Yang, H.; Yu-Hung, C.; Sasaki, T.; Morin, J. -F.; Guerrero, J. M.; Kelly, K. F.; Tour, J. M. Surface-rolling molecules. J. Am. Chem. Soc. 2006, 128, 4854-4864.

[52] Shirai Y.; Morin, J. -F.; Sasaki, T.; Guerrero, J. M.; Tour,
J. M. Recent progress on nanovehicles. Chem. Soc. Rev. 2006, 35, 1043-1055.

[53] Morin, J. -F.; Shirai, Y.; Tour, J. M. En route to a motorized nanocar. Org. Lett. 2006, 8, 1713-1716.

[54] Sasaki, T.; Tour, J. M. Synthesis of a dipolar nanocar. Tetrahedron Lett. 2007, 48, 5821-5824.

[55] Sasaki, T.; Morin, J. -F.; Lu, M.; Tour, J. M. Synthesis of a single-molecule nanotruck. Tetrahedron Lett. 2007, 48, 5817-5820.

[56] Morin, J. -F.; Sasaki, T.; Shirai. Y.; Guerrero J. M.; Tour, J. M. Synthetic routes toward carborane-wheeled nanocars. J. Org. Chem. 2007, 72, 9481-9490.

[57] Sasaki, T, Osgood, A. J.; Alemany, L. B.; Kelly, K. F.; Tour, J. M. Synthesis of a nanocar with an angled chassis: Towards circling movement. Org. Lett. 2008, 10, 229232.

[58] Sasaki, T.; Tour, J. M. Synthesis of a new photoactive nanovehicle: Nanoworm. Org. Lett. 2008, 10, 897-900.

[59] Sasaki, T.; Osgood, A. J.; Kiappes, J. L. Kelly, K. F.; Tour, J. M. Synthesis of a porphyrin-fullerene pinwheel. Org. Lett. 2008, 10, 1377-1380.

[60] Sasaki, T.; Guerrero J. M.; Tour, J. M. The assembly line: Self-assembling nanocars. Tetrahedron 2008, 64, 85228529.

[61] Morgan, D. A.; Sloan, J.; Green, M. L. H. Direct imaging of o-carborane molecules within single walled carbon nanotubes. Chem. Commun. 2002, 2442-2443.

[62] Bodwell, G. J.; Miller, D. O.; Vermeij, R. J. Nonplanar aromatic compounds 6. [2]Paracyclo[2](2,7)pyrenophane. A novel strained cyclophane and a first step on the road to a "Vögtle" belt. Org. Lett. 2001, 3, 2093-2096. 